\title{
MicroscopyPioneers \\ Pioneers in Optics: Georges de Buffon
}

From the website Molecular Expressions created by the late Michael Davidson and now maintained by Eric Clark, National Magnetic Field Laboratory, Florida State University, Tallahassee, FL 32306

eclark@magnet.fsu.edu

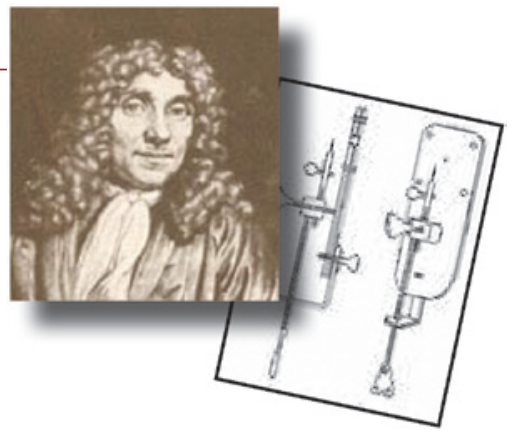

\section{Georges de Buffon} (1707-1788).

Born Georges-Louis Leclerc, the eighteenth-century natural historian, mathematician, and scientist who pioneered drastic alterations in the design of lenses used in lighthouses, is often better known as Georges de Buffon, a name associated with an estate he inherited from his mother when he was about 25 years old. Buffon's father was Benjamin Leclerc, the Lord of Dijon and Montbard, and his mother, whom he often credited for his significant intellectual capacity, is said to have been a woman of learning. Buffon attended a Jesuit college in Dijon and had a proclivity for mathematics, though his father persuaded him to the study of law, which he embarked on in 1723. By 1728, however, Buffon had enrolled at Angers University and changed his focus to science and mathematics. His studies at Angers were ended prematurely

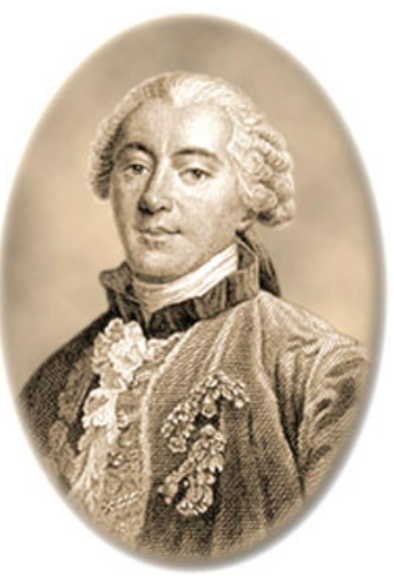
due to his forced exit from the institution, which was caused by his involvement in a duel. He subsequently toured Europe before eventually settling in Montbard.

Buffon's earliest work consisted of mathematical inquiries and translations of scientific works, including those of Sir Isaac Newton. His translation of a text written by Stephen Hales on plant physiology attracted him to biology, and the field would come to dominate his studies. Buffon relocated to Paris in his late twenties and there became familiar with many of the leading scholars of the day. He became a member of the French Academy of Sciences, and in 1739, was appointed keeper of the French botanical gardens then known as Jardin du Roi, but today referred to as the Jardin des Plantes. Buffon greatly expanded the gardens and was central in transforming them into a popular location for research. Buffon's interest in biology culminated in his 36-volume Histoire naturelle, générale et particulière, which encompassed the bulk of the information then known about the natural world. He had intended to write another 14 volumes but was unable to complete the cumbersome task before his death. Many of the ideas presented in Buffon's writings on natural history were groundbreaking. For instance, he was the first to suggest that the planets were formed from a collision between a comet and the sun, and he also made significant contributions to evolutionary theory, which would influence Charles Darwin.

Buffon's interest in natural phenomena led him to the study of light, mirrors, and lenses. His method of constructing concave mirrors continues to be used in modern times, and one of his inventions was a special mirror that could be used as a weapon by focusing sunlight intensely onto flammable objects. He is most important in optics, however, for his realization in 1748 that only the outer surface of a lens is necessary for the bending of light. This discovery was especially significant to the shipping industry, which was heavily dependent on lighthouses to keep ships from running aground or becoming lost at sea. In the eighteenth century, France was interested in constructing numerous new lighthouses along its coasts, but the traditional two-sided lenses used were extremely large and heavy as well as costly. By cutting away the inner surface of lighthouse lenses, however, as suggested by Buffon, the government could more easily establish the new structures and at a much more reasonable price. Notably, Buffon's redesign of the lens did not increase its magnification capacity. This important improvement would come several decades later at the hands of the French physicist Augustin Fresnel.

The health of Buffon began to deteriorate in 1785, and he died three years later in Paris. Upon his deathbed he is said to have spoken the following words: "I declare that I die in the religion in which I was born...I declare publicly that I believe in it." This final avowal is interesting in light of earlier troubles he had with the Church, which took issue with many of his claims regarding evolution and the age of the Earth (which he suggested was much older than the Church allowed). In fact, his ideas were so controversial among the devout that Catholics had publicly burned his books during his lifetime. 


\section{User-friendly Software for 2D/3D Image Analysis}

Impressive renderings are just the beginning. From high-definition exploration into the details and properties of 3D datasets to advanced image processing, segmentation, and quantification, Dragonfly software delivers the features microscopists need to accomplish meaningful results quickly and confidently. Fully extensible, Dragonfly lets researchers customize their workflows to fully understand complex phenomena and reveal important findings with easy-to-produce, high-impact animated sequences.

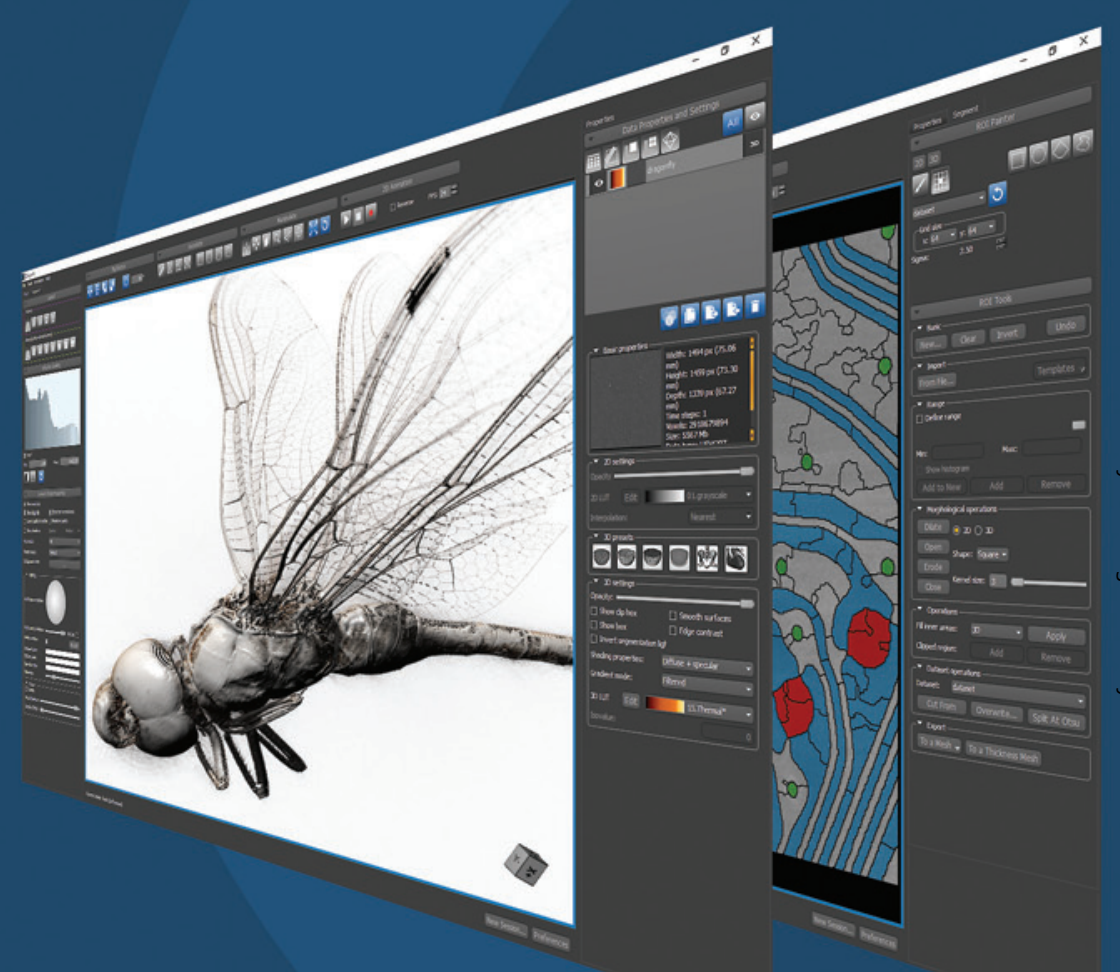

\section{The must-have image analysis solution for microscopists} Dragonfly is now free for non-commercial use*

\section{Dragonfly Features}

Integrated within an easy-to-learn interface and featuring an extensive set of industry-leading tools for the visualization, transformation, segmentation, measurement, and quantification of image data acquired by microscopy technologies, Dragonfly is simply the smartest choice for solving demanding research problems.

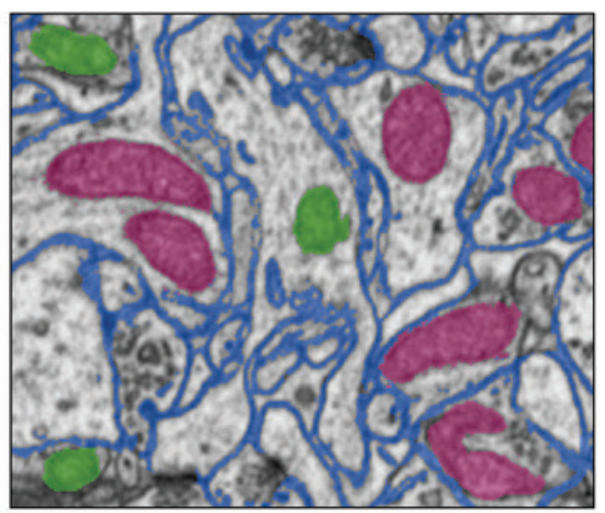

SEGMENT FEATURES OF INTEREST

Dragonfly pushes the envelope of image processing and quantification by providing a multi-faceted machine learning engine, superpixel methods, 2D histographic segmentation, and other innovative tools to label features of interest with ease and precision.

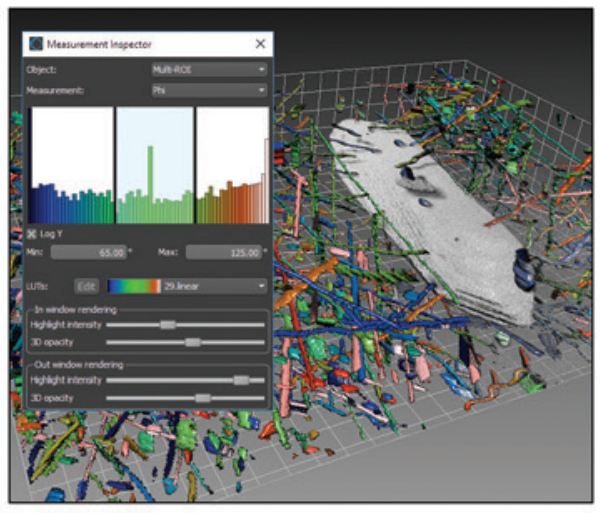

QUANTIFY AND ANALYZE

Dragonfly's quantification and analysis tools provide powerful options for counting, measuring, and characterizing image features. Interactive inspection with color and opacity mapping means that in-depth analyses can always be visualized in meaningful ways.

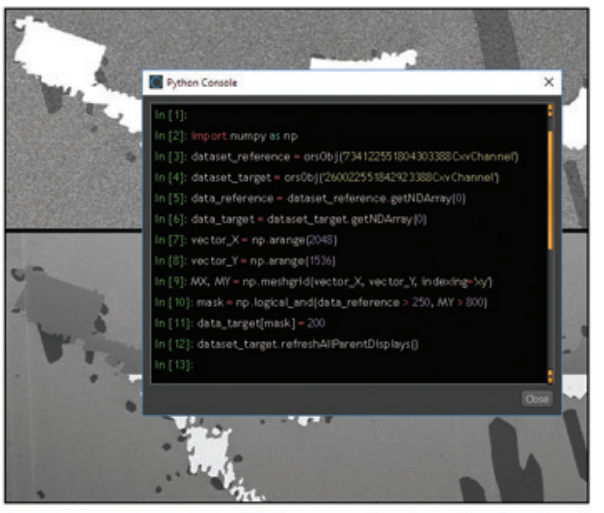

AUTOMATE AND EXTEND

Easy customization and extensibility with an embedded Python engine empowers users to record macros that automate repetitive tasks and to build plug-ins that leverage the powerful algorithms freely available in the Python ecosystem. 